Otterbein University

Digital Commons @ Otterbein

Nursing Faculty Scholarship

Nursing

9-5-2017

\title{
A map for successful CCNE accreditation
}

Jacqueline Haverkamp

Otterbein University

Alicia K. Ribar

University of South Carolina

Kay Ball

Otterbein University

Susan Butz

Otterbein University

John D. Chovan

Otterbein University

See next page for additional authors

Follow this and additional works at: https://digitalcommons.otterbein.edu/nurse_fac

Part of the Nursing Commons

\section{Repository Citation}

Haverkamp, Jacqueline; Ribar, Alicia K.; Ball, Kay; Butz, Susan; Chovan, John D.; Fried, Eva M.; Garrett, Brian; Hughes, Karen R. Dr; Keane, Patricia; Prusinski, Regina F.; and Shoemaker, Joy R., "A map for successful CCNE accreditation" (2017). Nursing Faculty Scholarship. 6.

https://digitalcommons.otterbein.edu/nurse_fac/6

This Article is brought to you for free and open access by the Nursing at Digital Commons @ Otterbein. It has been accepted for inclusion in Nursing Faculty Scholarship by an authorized administrator of Digital Commons@ Otterbein. For more information, please contact digitalcommons07@otterbein.edu. 


\section{Authors}

Jacqueline Haverkamp, Alicia K. Ribar, Kay Ball, Susan Butz, John D. Chovan, Eva M. Fried, Brian Garrett, Karen R. Hughes Dr, Patricia Keane, Regina F. Prusinski, and Joy R. Shoemaker 


\title{
A map for successful CCNE accreditation
}

\author{
Jacqueline Haverkamp ${ }^{\text {a,* }}$, Alicia K. Ribar ${ }^{\text {b }}$, Kay Ball ${ }^{\text {a }}$, Kacy Ballard ${ }^{\text {a }}$, Susan Butz ${ }^{\text {a }}$, John D. Chovan ${ }^{\text {a }}$, \\ Eva M. Fried ${ }^{a}$, Brian Garrett ${ }^{a}$, Karen Hughes ${ }^{a}$, Patricia Keane ${ }^{a}$, Regina Prusinski ${ }^{a}$, Joy R. Shoemaker ${ }^{\text {a }}$ \\ a Otterbein University, United States \\ ${ }^{\mathrm{b}}$ University of South Carolina, United States
}

\section{A R T I C L E I N F O}

\section{Article history:}

Received 28 February 2017

Revised 24 August 2017

Accepted 5 September 2017

Available online $\mathrm{xxxx}$

\section{Keywords:}

Accreditation

Evaluation plan

Organizational structure

CCNE recommendations

\section{Introduction}

Every nursing program works hard to achieve a successful accreditation. The Commission on Collegiate Nursing Education (CCNE) recently evaluated our nursing degree programs at the baccalaureate, master's and Doctor of Nursing Practice (DNP) levels. In addition, we had a joint specialty accreditation with the Council on Accreditation (COA) of Nurse Anesthesia Educational Programs. Most of the current faculty, lab and administrative staff had not experienced a site visit, but even so, our program achieved full accreditation status, with no compliance issues.We have received public recognition that our nursing program met all CCNE standards (Commission on Collegiate Education [CCNE], 2013b), but perhaps more importantly, the positive CCNE report affirmed theimportance ofthe time invested in planning, developing, and implementing structures and processes for program assessment and improvement.

The major purpose of CCNE accreditation is to ensure quality and integrity in baccalaureate and graduate nursing educational degree

\footnotetext{
* Corresponding author at: Otterbein University, 1 S. Grove Street, Westerville, $\mathrm{OH}$ 43081, United States.

E-mail addresses: jhaverkamp@otterbein.edu (J. Haverkamp), ribara@mailbox.sc.edu (A.K. Ribar), kball@otterbein.edu (K. Ball), kballard@otterbein.edu (K. Ballard), sbutz@otterbein.edu (S. Butz),jchovan@otterbein.edu (J.D.Chovan), efried@otterbein.edu (E.M. Fried), bgarrett@otterbein.edu (B. Garrett),khughes@otterbein.edu (K. Hughes), pkeane@otterbein.edu (P. Keane), rprusinski@otterbein.edu (R. Prusinski), jshoemkaer@otterbein.edu (J.R. Shoemaker).
}

programs through assessment of their mission, goals, and expected outcomes (CCNE, 2013b).The accreditors pay close attention to how well the evaluation plan functions, whether the curriculum meets appropriate American Association of Colleges in Nursing (AACN) essentials and other professional standards, and the adequacy of the resources to meet the mission of the program.In addition, achievement of the standards must be evident in the resources available for CCNE site visitors to review.

Despite an understanding that "ongoing self-assessment is key to effective participation in the accreditation process" (Ellis \& Halstead, 2012, p. 19), there is limited literature that specifically addresses how to integrate the processes and structures needed for successful accreditation into the workflow of the nursing program. Preparing for a CCNE accreditation requires multi-year planning of layered components and an extensive team effort to ensure that the program is successful in achieving all standards. It also provides the opportunity for selfassessment, identification of areas of program strength and areas for program improvement, and creation of a plan of action to address issues (CCNE, 2013c).

The purpose of this article is to provide nurse educators with recommendations on how to develop the needed structures and processes that lead to accreditation success. We provide a comprehensive list of 28 recommendations, a timeline for completion of tasks, and specific information on how to document the achievement of the four CCNE Standards. The first two recommendations deal with two vital structures that comprise a well-functioning program: an effective committee structure and a robust evaluation plan. Recommendations 3 to 12 concern the process steps for preparing for an accreditation visit and are aligned with a timeline for completion. The remaining recommendations address how to document compliance with each CCNE standard.

\section{Structure}

Recommendation 1. Create an effective program committee structure and distribute the preparatory work among the committees to ensure faculty participation.

The structure of our nursing programs included committees with responsibility to assess and evaluate elements of the program in relation to standards on an ongoing basis. An effective committee structure and functioning evaluation plan were at the heart of our successful accreditation. Table 1 presents a sample page from our 

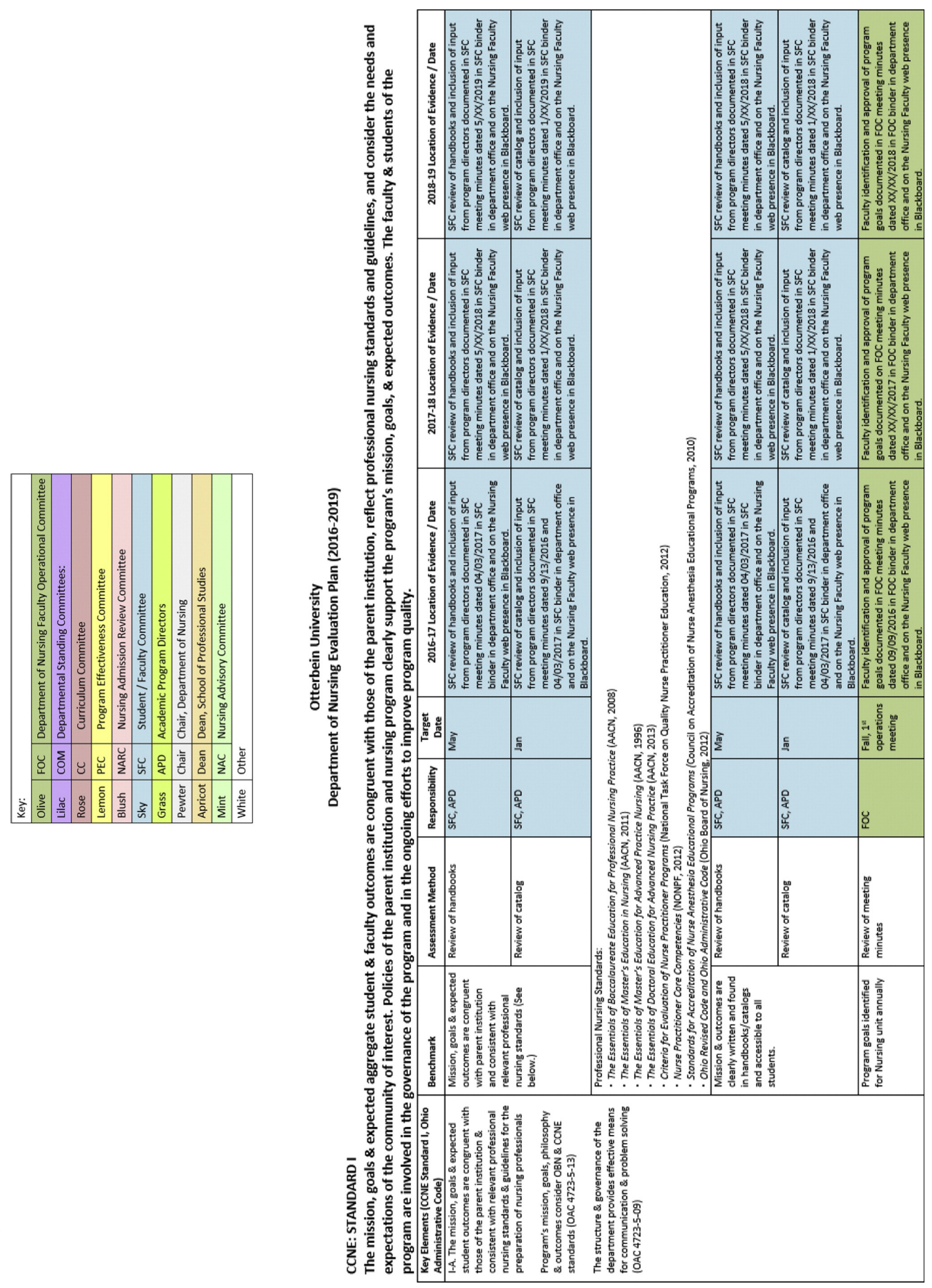
evaluation plan.The Evaluation Committee oversaw program effectiveness and the Curriculum Committee handled curricular changes and course evaluations. The responsibility for the standards was delegated to the appropriate established committee. For example, the Curriculum Committee was responsible for CCNE Standard III (Program Quality) and the Evaluation Committee was responsible for CCNE Standard IV (Program Effectiveness). The responsibility for the standard extended beyond writing a draft of that standard for the report; the ongoing work of the committee was to ensure that the requirements for each respective standard were met and evaluated as part of a continuous improvement process (Ellis \& Halstead, 2012). Our effective model was to assign each faculty member to at least one nursing program committee. All faculties were involved with maintaining the requirements of the standards on a continual basis and were part of writing the self-study, based on their committee representation. This meant that each faculty member would know at least one standard of the self-study very well, and ensured that they could answer questions from CCNE accreditation visitors about the respective standard.

Identified committees within a department were assigned these responsibilities and kept the larger body informed through reports at scheduled faculty meetings. These committees met at least monthly and addressed topics noted within the evaluation plan. At regularly scheduled faculty meetings, committees as well as other ad hoc groups provided oral updates about the ongoing evaluation processes.
Recommendation 2. Create a robust and functioning evaluation plan that is implemented for continuous quality improvement.

An important part of the structure was a functional evaluation plan which was based on applicable professional standards.It was a working document that was carried out by all, thus supporting the creation of the self-study report. The evaluation plan addresses CCNE standards and key elements, State Board of Nursing standards, and standards from other professional organizations, such as the National Task Force on Quality Nurse Practitioner Education criteria (National Task Force on Quality Nurse Practitioner Education, 2016).Most of the outcomes addressed in the evaluation plan were program generated; however, CCNE has defined specific expectations for selected Standard IV outcomes: program completion rates, National Council on Licensure Examination (NCLEX-RN) and certification exam pass rates, and employment rates (CCNE, 2013a). Our quality improvement processes addressed these outcomes and changes were implemented as needed.

\section{Process timeline}

A timeline for preparing a self-study (similar to the timeline identified in Table 2) is driven by the expected date of the CCNE reaccreditation.

Three to five years prior to visit

Table 2

Timeline.

\begin{tabular}{|c|c|c|}
\hline When & Who & \\
\hline $3-5$ years & All faculty & Conduct nursing unit retreat to evaluate and revise the mission and outcomes as needed. \\
\hline $3-5$ years & Evaluation Committee & $\begin{array}{l}\text { Examine evaluation plan to make sure that all required areas are addressed (See Standard IV).Develop a yearly timeline for evaluation } \\
\text { of program components; ensure that all components are being evaluated in an ongoing basis, changes are made as needed, and } \\
\text { recorded.Plan at least an annual evaluation day for all faculty to discuss evaluation findings and recommend changes. }\end{array}$ \\
\hline $3-5$ years & Curriculum Committee & $\begin{array}{l}\text { Examine curriculum so that it reflects Essentials and other professional guidelines. Crosswalk each program with appropriate national } \\
\text { guidelines. Revise curriculum to reflect any needed changes identified during mid-cycle report or gaps from crosswalk. }\end{array}$ \\
\hline $3-5$ years & Relevant committees & Integrate student participation as part of major decision-making committees, such as curriculum and evaluation committees. \\
\hline On-going & Evaluation committee & $\begin{array}{l}\text { Collect needed statistics to show NCLEX-RN, certification exam pass rate and completion rate outcomes are met; evaluate these } \\
\text { outcomes. }\end{array}$ \\
\hline $2-4$ years & Curriculum committee & $\begin{array}{l}\text { Adjust curriculum addressing any identified areas of concern from evaluation plan or outcomes such as NCLEX-RN and certification } \\
\text { exam pass rates, completion rates and other outcomes. }\end{array}$ \\
\hline On-going & $\begin{array}{l}\text { Chief Nurse } \\
\text { Administrator }\end{array}$ & $\begin{array}{l}\text { Plan regular meetings (annual or semiannual) with advisory committee of communities of interest - employers, community members, } \\
\text { and other key persons. }\end{array}$ \\
\hline 2 years & $\begin{array}{l}\text { Relevant committee or } \\
\text { workgroup }\end{array}$ & $\begin{array}{l}\text { Review governing documents and revise as needed; review all policies; update organizational charts; review all publications and } \\
\text { website for accuracy and consistency. }\end{array}$ \\
\hline $2-3$ years & Faculty & $\begin{array}{l}\text { Compile credentials of faculty and correct any deficits. For example, if faculties are not represented well in institutional governance, } \\
\text { develop a plan for faculty to seek needed committee memberships and leadership positions. }\end{array}$ \\
\hline $1-2$ years & $\begin{array}{l}\text { Chief Nurse } \\
\text { Administrator }\end{array}$ & $\begin{array}{l}\text { The chair or dean sends letter to CCNE requesting site visit and proposing dates for on-site evaluation. Develop timeline for unfinished } \\
\text { work, and remedies for shortfalls.Set assignments for faculty work groups and staff; obtain and study documents pertinent to self-study } \\
\text { such as AACN Essentials and policy documents of the institution. Set deadlines for completion of drafts. } \\
\text { Assignments should arise from the responsibilities of committees; for example, curriculum committee should write Standard III, } \\
\text { evaluation committee Standard IV, and so on. } \\
\text { Identify key figure to monitor progress of self-study; assign keeper of current draft. }\end{array}$ \\
\hline $\begin{array}{l}1 \text { year - } \\
6 \text { months }\end{array}$ & Writing groups & $\begin{array}{l}\text { Complete first draft of self-study -send to all faculties for revision and editing; consider assigning one editor for revision for consistency } \\
\text { in writing style and voice. }\end{array}$ \\
\hline 6 months & Chief Nursing & Make sure key administrators and stakeholders have date/time for visit in calendar. \\
\hline
\end{tabular}

Revisit all publications and websites to ensure accuracy.

Complete revisions based on editing suggestions.

Arrange visits to clinical sites, arrange visitors to meet with students, preceptors, and employers.

Secure lodging, and arrange transportation from lodging if needed.

Inform communities of interest of visit; Inform students; post an announcement about the visit on program website; send letter to stakeholders. Set the agenda, set up appointments with institutional staff and administration per visitor agenda; and set up meetings with students and faculty.

Confirm all arrangements.

2 months Chief Nursing Administrator

1 month Curriculum committee

Set up resource room and on-line resource access for visitors.

1 month Chief Nursing

Administrator

Meet with Provost and President and review highlights of the accreditation process; provide talking points; provide other staff and administration with talking points; confirm/remind students and faculty of meetings with visitors. 
Recommendation 3. Conduct a thorough self-assessment of the mission, resources, curriculum, and evaluation plan including all faculty via a retreat and biennial assessment days.

Three years prior to the scheduled visit, the nursing program conducted a thorough assessment of the mission, resources, curriculum, and evaluation plan. A Continuous Improvement Progress Report (CIPR) is required by CCNE at the midpoint of the accreditation cycle, and completion of this report is a good time to assess these standards.A one-day retreat was a productive way for faculty to discuss deeper thoughts about what the mission should be. Results from these conversations were merged into consensus statements.

A working, successful evaluation plan that was explicitly tied to CCNE standards ensured that any deficiencies were identified early enough to make changes which were then evaluated.The program needed to show that outcomes were measured, systematically assessed, and evaluated. This was a process of continual improvement (Ellis \& Halstead, 2012).Two evaluation days were scheduled annually for all faculties to discuss evaluation findings and to recommend changes. If an early review of resources indicated any deficits, there was time to initiate remedies.

One to three years prior to visit

Recommendation 4. Review the CCNE Procedures for accreditation early and often.

At this point, we reviewed the CCNE Procedures Manual (CCNE, 2014) for detailed descriptions of the process of the review. Utmost familiarity with the CCNE expectations is imperative for successful accreditation.

Recommendation 5. Implement and evaluate changes generated from the assessment, and from faculty retreats and assessment days.

One to three years prior to the visit, the changes that emerged from the assessment of the mission, resources, curriculum, and evaluation plan were in place. After implementation, evaluation of these new changes occurred so that the assessment feedback loop was complete. Program outcome measures were monitored, particularly student learning outcomes, and those outcomes that are specified by CCNE, such as NCLEX-RN pass rates, certification pass rates, program completion rates, and employment rates. The appropriate committee addressed identified deficiencies.

Recommendation 6. Consider whether to align accreditation cycles and site visits to streamline preparation activities.

Based on varying dates when individual degrees and programs were initiated, our department had accreditation visits scheduled for different years for some of its programs. The nursing program decided to ask CCNE to revise the scheduled accreditation visits so that our visits could be combined, accelerating our DNP accreditation timeline. We also negotiated a joint accreditation visit with CCNE and the COA of Nurse Anesthesia Educational Programs, delaying the COA visit by 6 months. All programs were evaluated during the same visit and will now be on the same timeline going forward.

There are advantages and disadvantages to either combining all nursing programs in one CCNE accreditation visit or scheduling a joint visit with another accreditor. The combined or joint accreditation visit will be more extensive, with more visitors, and require more preparation and coordination. In addition, there will be a 10 year gap between accreditation visits, creating the possibility that vigilant attention to standards may be attenuated with the longer time between visits. On the other hand, documentation of some of the key elements within the standards arethe same, so this would be a more efficient approach and require fewer visits going forward.
Six months to one year prior to visit

Recommendation 7. Write the first draft of the self-study early.

One year prior to the visit, the writers started drafting the accreditation report. Faculty teams, from working committees identified within the Evaluation Plan, wrote sections of the report as they applied to the duties for which they had responsibility.For example, the Curriculum Committee discussed and reflected upon the key elements of Standard III and how to highlight the program's successful outcomes. Each member of the Curriculum Committee was asked to select one key element to prepare. This structure allowed for distribution of workload and collaboration as well as giving members the opportunity to work on elements of particular interest. After the initial work on Standard III key elements, the Curriculum Committee found several tasks that required additional preparation and collection of evidence to support the program's outcomes. Utilizing program catalogs, university websites, and plans of study documents, information was gathered for each program level, outlining the congruence of student learning outcomes with program objectives and professional guidelines (American Association of Colleges of Nursing [AACN], 2006; American Association of Colleges of Nursing, 2011; National Task Force on Quality Nurse Practitioner Education, 2016; COA of Nurse Anesthesia Educational Programs, 2016).

Recommendation 8. Review and audit all publications, syllabi, and publicly available materials.

One year prior to the visit faculty audited all publications, such as course catalogs, websites, program advertising, and promotional materials to ensure that they were accurate and consistent. We also audited each syllabus, reviewing course objectives, course content, grading criteria, rubrics, and, for clinical nursing courses, clinical evaluation criteria. The course objectives in syllabi were labeled with the corresponding Essential (AACN, 2006; 2008; 2011), which facilitated the compilation of alignment tables.

Three to six months prior to visit

Recommendation 9. Select one writer to be the consistent voice and writing style for subsequent drafts and the final version, gaining feedback at each draft from all faculties.

Even though several faculty members collectively wrote the first draft of the self-study, one person wrote the second draft. Having a consistent voice using the same writing style and grammatical conventions added to the readability of the self-study. We included electronic links throughout the draft that accessed evidence supporting achievement of the standards, such as web pages. After the second draft was written, we made it available to all faculty and selected individuals to review, edit, and correct, as needed.

Recommendation 10. Prepare for site visitation by communicating with the team leaders, informing all relevant parties, and arranging accommodations for the site team.

The communities of interest were informed of the scheduled CCNE visit through website notifications and email. Reservations were made well in advance for the hotel accommodations for the site visitors.The visiting team will work in the evening at the hotel, so hotel arrangements should include individual rooms with desks and internet access, a business center with a printer, 
and a meeting space for small group work. Communicate with the team about any other special needs, such as a printer in their meeting space.

Through communication with the CCNE team leader, we created an agenda that included meetings with principal administrators and others. We made appointments with the university president, the provost, and other deans to ensure their availability, and meetings were arranged with communities of interest, such as clinical partners, preceptors, and students. It is important to prepare the key people who will be meeting with the visitors with information on the accreditation process and talking points about the program(s) under review. A mock site visit might be helpful in preparing students and faculty to respond to the kinds of questions that site visitors may have. For our preparation, we conducted a mock game show with faculty being quizzed on aspects of our program evaluation process and accreditation standards. This proved to be an excellent method for learning and validation of knowledge, was enjoyable, and helped to relieve pre-visit jitters.

One month prior to visit

Recommendation 11. Delegate responsibility of the resource room preparation to one committee with input from all committees and faculty members, and prepare the resource room.

The Curriculum Committee had major responsibility for preparing the resource room, but all faculty and staff contributed to it. The resource room was the workroom where the site visitors had access to all printed documentation, as well as computer access for electronic documentation. Our resource room included extensive work surfaces and space for file cabinets and manuals.Office supplies, such as staplers, markers, pens, pencils, paper clips, and sticky notes were available, as well as snacks and beverages. The room allowed for privacy and was locked at the end of the day.Because accreditation teams may differ in how much documentation they want in paper versus electronic format, our program communicated with the team leaders as to their preferences.

We organized paper documentation utilizing large binders, designated for each standard, with organizing tabs for each key element of the standard. All documentation for the standard was placed in the binder, if feasible. For example, if the mission of the department was discussed at a retreat, we included the minutes of that retreat, highlighted where the mission was discussed, and filed those minutes under the appropriate key element and standard. Consequently, visitors could easily document that the key element was met. Syllabi from each course taught in the preceding 3 years were also placed in the binders. The binders also contained minutes from faculty meetings, committee meetings, and course evaluations for the previous 3 years.To show student work, hanging files organized in filing cabinets by course number for each course were used.At least one example of excellent student work and one example of student work requiring faculty feedback were included.Paper copies of course catalogs and handbooks were available. Other file drawers included preceptor evaluations, evaluations of clinical units, and other relevant documentation.

Recommendation 12. To enhance accessibility, create a flash drive containing all appropriate documentation for each member of the visitation team

For maximum utility and ease of access to resources, we created a flash drive for each member of the accreditation team. The selfstudy document included both internal and external electronic hyperlinks within the document text. Internal hyperlinks were targeted to appendices, tables, and other sections of the document.
Hyperlinks to external documentation, such as handbooks, minutes, and catalogs, were also added when copying the self-study to a flash drive.

\section{Documentation of standards}

Moving beyond structure and timeline considerations in meeting CCNE expectations, the following is a discussion of how programs can demonstrate compliance with each CCNE standard, both with ongoing processes and in the self-study report.

Recommendation 13. Address every key element under each standard and have evidence of that you meet that element, either through the narrative, or with a table or appendix in the self-study, or with a document filed either in the resource room or electronically.

CCNE provides excellent guidance for meeting their standards for accreditation (CCNE, 2013b,c). CCNE recently published a supplemental resource to help assess student achievement, which is very useful in determining how to assess and interpret the key elements in the standards (CCNE, 2016).

\section{Standard I}

Standard I concerns congruency of the nursing program mission, goals and outcomes with the mission of the institution. The mission, outcome and goals also need to reflect professional nursing standards and guidelines, and take into consideration the communities of interest (CCNE, 2013b).

Recommendation 14. Examine Standard I early in the accreditation timeline, allowing time to make the necessary changes.

We examined the mission and goals early in the accreditation timeline. If there had been incongruence between the program and the institution, there would have been time to change, to have those changes reflected in outcomes and curriculum, and to evaluate those changes prior to the accreditation visit

Recommendation 15. Develop and interact with an advisory committee from the communities of interest.

One way to demonstrate responsiveness of the nursing program to the communities of interest, as defined by the nursing program, is with a robust and functioning Advisory Committee. Our Advisory Committee included consumers, the nursing department chair, key faculty, clinical partners, employers of graduates, other nurse educators, administrators in health care agencies, preceptors, students, and alumni. We increased the meeting time from annually to semi-annually and revitalized the committee by recruiting more active members and clinical partners.

Recommendation 16. Include faculty and students in committee structures.

In our program, both faculty and students are expected to participate in program governance.Each committee has a mechanism for student participation, and faculties are expected to hold membership in at least one departmental committee. As a group, our department discussed upcoming university-wide committee elections, and who would sit for election, ensuring nursing program representation on important university committees.

\section{Recommendation 17. Document outcomes for Standard I in tables.}

Many of the outcomes for Standard I can be demonstrated through tables. We aligned the nursing unit goals with those of the institution with a table, with one column of descriptors of the nursing unit mission matched up with similar descriptors of the institutional mission. 
Recommendation 18. Document examples of written expectations for faculty.

To demonstrate written expectations for teaching, scholarship, service, clinical practice, and advising, we include excerpts from faculty manuals. Faculty involvement in governance wasdemonstrated with a chart that showed faculty membership in university and departmental committees.Supporting documentation included minutes from relevant meetings that reflected decision-making related to mission and governance.

\section{Standard II}

In Standard II, CCNE is evaluating if the parent institution supports the nursing program with resources sufficient to achieve its mission, goals, and outcomes (CCNE, 2013b).

Recommendation 19. Use the nursing budget to demonstrate support of the nursing programs.

One indicator of support from the university is the nursing budget. In writing the self-study, we emphasized budget decisions that reflected support for the program (such as budget increases to support new programs), recent budget allotments for special projects (such as lab renovations), and support for faculty development (such as conference money and stipends or time releases for scholarship or course development).

Recommendation 20. Demonstrate examples of physical, technical, and student learning support infrastructure and services.

The self-study should describe support services, physical resources, and information technology services. To document adequacy of the information technology services, we included descriptions of course management systems for courses and their support. Documentation of library resources included a description of the comprehensive library resources of the institution. Other physical resources, such as library classrooms, computer labs, archives, and online resources (for example, access to major medical/nursing databases, such as CINAHL, Medline, and Cochrane Reviews) were described.Our institution is part of a regional consortium with wider access to journals and books; this resource was emphasized.

Our students evaluate library and information technology resources as part of each course evaluation, and these data were included to demonstrate responsiveness to student needs.

The self-study outlined other ways that students are supported, including information on how students are assigned an academic advisor, and the advisor's role in aiding students to develop their programs of study. Discussing financial aid resources that are available to students, such as loans and scholarship opportunities, was important. Other support services were outlined in detail in the self-study, such as the student health center, career planning, academic and research support, and admission services.

\section{Standard III}

Standard III is concerned with program quality from a curricular and teaching-learning practice perspective (Commission on Collegiate Nursing Education, 2013b).

Recommendation 21. Use descriptive text and tables to demonstrate the relationship between student learning outcomes and the program's mission and goals.

Congruency of the curriculum with the program's mission and goals was described with tables. Incorporation of professional standards and guidelines into the curriculum was also demonstrated with tables that align the relevant Essentials (AACN, 2006; 2008; 2011) with program course objectives.

Recommendation 22. Document curriculum using sample plans and narrative descriptions, all linking back to learning outcomes.

CCNE is looking for curriculum that is logically structured for achievement of outcomes (AACN, 2006; 2008; 2011; ). We provided sample curricular plans, a narrative on how the curriculum was organized, rationale for its organization, and how it built on foundational knowledge. Descriptions of the variety of teaching methods in the self-study, as well as syllabi that document teaching-learning methods and strategies, demonstrated attainment of this key element.

The curriculum for each program track included experiences that enabled students to integrate new knowledge and demonstrate achievement of program outcomes as evaluated by faculty. The curricular plan, along with the teaching-learning practices, reflected the needs and expectations of the identified community of interest through several modalities. The program utilized internal and external input from several communities of interest. The methods varied from robust student input at the faculty, course, department, college, or university levels to more indirect input, such as advisory boards, graduate surveys, and feedback from alumni and employers.

Recommendation 23. Evaluate student performance, curriculum, and teaching and learning practices.

Evaluation of student performance involves multiple direct and indirect measures. We included direct measures, such as formative and summative course assessments based upon specific course objectives. Student outcome data contained both individual examples, such as individual student papers or projects, and aggregated data. Data were aggregated from grading rubrics for course projects to provide direct measures of student learning outcomes. Indirect measures, such as course evaluations and faculty evaluations, were also used. The Curriculum Committee monitored course performance and reported the appropriate data in the evaluation plan while recommending course revisions based on the review. This provided the data necessary to inform the department's continuous evaluation and improvement of all programs.

\section{Standard IV}

Standard IV is concerned with the assessment and achievement of program outcomes (CCNE, 2013b).

Recommendation 24. Use a color-coded master grid to track the working evaluation plan, including columns for the standards, the method for measuring the standards, and the timeline for their assessment.

The key to achieving Standard IV is to have a working evaluation plan, as well as a mechanism for tracking the plan. We used an Evaluation Plan Master Grid that listed all the evaluation criteria, not only from CCNE, but also from any other accreditation entities, such as the State Board of Nursing, in one location, to help with tracking. The Evaluation Plan Master Grid contains a timeline for criteria review, the party responsible for doing the criteria review, the mechanism for measurement, and, most importantly, the location of the evidence to support that the criteria have been met.Table I presents an example of one of the pages from our Evaluation Plan Master Grid. The reader will note that the rows are color-coded. This scheme enables each of our major stakeholders, such as the dean, program chair, and the various departmental committees, to quickly find items for which they are responsible. 
Recommendation 25. One committee monitors the evaluation plan.

The verification of completion of outcome evaluation is best tracked and monitored by one central committee. In our case, this task is done by the Program Effectiveness Committee, which also updates and maintains the Evaluation Plan Master Grid. Developing a working evaluation plan and a mechanism for systematic tracking of outcomes aids in the overall work associated with Standard IV and allows all stakeholders to fully understand and take part inongoing program improvements. The evaluation plan involves examining outcomes both at the individual and aggregate levels. For example, CCNE expects faculty outcomes, such as teaching or scholarship, to be presented for individual faculty as well as for the group.

Recommendation 26. Maintain evaluative data in a central location that is backed up regularly and accessible.

All data that are key elements in evaluating program outcomes, not only for external use but also for internal use within the department, college or university, should be collected and maintained in a central location. We included the first-time pass rate on the NCLEX-RN,graduate program certification exam pass rates, summary data from surveying recent graduates, and surveying information from employers of graduates. Any additional evaluation processes at the program or university level should also link to the Essentials and CCNE criteria (AACN, 2006; 2008; 2011; CCNE, 2013b; COA of Nurse Anesthesia Educational Program, 2016; National Task Force on Quality Nurse Practitioner Education, 2016).

Recommendation 27. Analyze outcome data for strengths and deficits, as well as patterns, and from these, develop an improvement plan.

The self-study described how outcomes are measured in direct andindirect ways, and how the outcomes met measures of success. Analyses of the strengths and deficits of the outcomes that contribute to the effectiveness of the program were conducted, and plans for action were outlined. The achievement of goals set by the program were examined for patterns or concerns to assist in program improvement.

\section{Conclusion}

A successful accreditation is possible with a few people doing all the work, but when several faculties, or an entire department, work together as a team, the results have a beneficial impact. All faculties learn the strengths of peer members and use this knowledge to accomplish other synergistic projects.Further, this process can reinforce the necessity of routinely keeping supporting documentation in proper order for quick retrieval and reference. The establishment of a repository for all pertinent documents, available to all faculties, is vital to allow quick retrieval and reference, not only for long-term compliance but also for daily workflow efficiency.

Preparing for a CCNE site visit requires multi-year planning and an extensive team effort to ensure that the program is successful in achieving all standards for CCNE accreditation. Developing structures and processes that allow for continual evaluation and improvement is ultimately the best practice for successful CCNE accreditation. Maintaining a functional evaluation plan, ensuring that curriculum meets appropriate Essentials (AACN, 2006; 2008; 2011) while integrating specialty professional standards, and maintaining supporting evidence in an organized, readily accessible fashion, allows for continual improvement and adherence to CCNE standards.

\section{References}

American Association of Colleges of Nursing (2006). Essentials of baccalaureate education for professional nursing practice. Retrieved from http://www.aacn.nche.edu/ education-resources/essential-series.

American Association of Colleges of Nursing (2008). Essentials of doctoral education for advanced nursing practice. Retrieved from http://www.aacn.nche.edu/educationresources/essential-series.

American Association of Colleges of Nursing (2011). Essentials of master's education in nursing. Retrieved from http://www.aacn.nche.edu/education-resources/essentialseries.

Commission on Collegiate Nursing Education (2013a). Guidelines for assessment of student achievement. Retrieved from http://www.aacn.nche.edu/ccne-accreditation.

Commission on Collegiate Nursing Education (2013b). Standards for accreditation of baccalaureate and graduate nursing programs. Amended 2013. Retrieved from http:// www.aacn.nche.edu/ccne-accreditation/standards-procedures-resources/ baccalaureate-graduate/standards.

Commission on Collegiate Nursing Education (2013c). Self-study template. Retrieved from http://www.aacn.nche.edu/ccne-accreditation/standards-proceduresresources/baccalaureate-graduate/program-resources.

Commission on Collegiate Nursing Education (2014). Procedures for accreditation of baccalaureate and graduate degree nursing programs. Retrieved from http://www.aacn. nche.edu/ccne-accreditation/standards-procedures-resources/baccalaureategraduate.

Commission on Collegiate Nursing Education (2016). Supplemental resources for the standards for accreditation of baccalaureate and graduate nursing programs. Retrieved from http://www.aacn.nche.edu/ccne-accreditation/standards-proceduresresources/baccalaureate-graduate.

Council on Accreditation of Nurse Anesthesia Educational Programs (2016). 2004 Standards for accreditation of nurse anesthesia programs (revised 2016). Retrieved from http://home.coa.us.com/accreditation/Documents/2004\%20Standards\%20for\% 20Accreditation\%20 of\%20Nurse\%20Anesthesia\%20Educational\%20Programs,\% 20revised\%20June\%202016.pdf.

Ellis, P., \& Halstead, J. (2012). Understanding the Commission on Collegiate Nursing Education accreditation process and the role of the continuous improvement progress report. Journal of Professional Nursing, 28(1), 18-26. https://doi.org/10.1016/j.profnurs. 2011.10.004.

National Task Force on Quality Nurse Practitioner Education (2016). Criteria for evaluation of nurse practitioner programs ( $5^{\text {th }}$ Edition ) Retrieved from http://www.nonpf.org/? page $=15$. 